\title{
Antimicrobial activities of Six Types of Wheat Bran
}

\author{
F.A.Elhassan ${ }^{1}$, Suad.A.Gadir2and H.O, Dahawi ${ }^{3}$. Fathia.A.Adam ${ }^{4}$ \\ ${ }^{I}$ Department of Chemistry, Faculty of Arts and Sciences Bbelkrn, University of Bisha, Kingdom of Saudi Arabia \\ ${ }^{2}$ Department of Chemistry, Faculty of Education, Alzaeim Alazhari University, Khartoum, Sudan \\ ${ }^{3}$ Department of Chemistry, Faculty of Science and Humanities, shaqra university, Kingdom of Saudi Arabia \\ ${ }^{4}$ Department of Chemistry, Faculty of Arts and Sciences Bbelkrn, University of Bisha, Kingdom of Saudi Arabia
}

\begin{abstract}
Six types of wheat bran (Emam, Pohean, Wadielneel, Argeen, Pladi and Debeira) investigated for their biological and antioxidant activities. Physiochemical properties carried for their oil. The polar and nonpolar extracts showed antioxidant activity. These results showed the importance of the wheat bran types as nutritive and medicinal plant. All plant bran types investigated for its biological activity as antifungal and antibacterial. Some types of the plant bran extracts showed antibacterial activity towards Escherichia coli, Pseudomonasaeruginosa, Bacillus subtilis, and Staphylococcus aureus. In addition, some types of the extracts showed antifungal activity towards Candida albicans, and Aspergillusniger. Polar and nonpolar extracts of the plant bran types prepared. The petroleum ether extracts subjected to determination by GC/ MS. It showed different major fatty acids as Linoleic acid followed by Linolelaidic acid and then Palmatic acid. The ethanolic extract of Plaid type separated by column chromatography. The isolated constituents were structurally determined using spectrophotometric analysis as IR, UV, and GC/MS. The ethanolic extract components may be esters and ketones as suggested by GC/MS and their functional groups appeared in the IR readings.
\end{abstract}

Key Words: Wheat Bran (Emam, Pohean, Wadielneel, Pladi, Argeen, And Dibera), Antimicrobial activity (Antibacterial and Antifungal), Antioxidant activity.

\section{Introduction}

Wheat is a type of grass grown all over the world for its highly nutritious and useful grains. The wheat kernels have three parts: (sometimes called a wheat berry):

1. The Bran is the hard outer covering of the wheat kernel, high in fiber and nutrients.

2. The Germ is the nutrient rich embryo that will sprout and grow into a new wheat plant.

3. The Endosperm is the biggest part (83\%), the "insides" of the kernel mostly starch ${ }^{1}$.

Wheat bran is not only a good source of dietary fibers ${ }^{2-3}$. But also rich source of various natural antioxidants including tocopherols, phenolic acids ${ }^{4,5}$. Antioxidants modulate cellular oxidative status, and prevent biologically important molecules such as DNA, proteins, and membrane lipids from oxidative damage and consequently reduce the risk of several chronic diseases including cancer and cardiovascular disease $e^{6-8}$. Tocopherols, phenolic acids and other antioxidants in wheat bran generally believed to be primarily responsible for its positive effects on cardiovascular diseases ${ }^{2-3-7}$. The compounds of wheat bran exhibited significant capabilities in scavenging free radicals, chelating metal ion oxidants; and reducing lipid oxidation at different conditions ${ }^{9,10}$.

\section{Wheat Bran Oil}

The major fatty acids of wheat bran oil were palmitic, oleic, linoleic and $\gamma$ - linolenic acids. Linoleic acid found in highest amount and it was present in the range from 52.2 to $60 \%$ of total identified fatty acids. Another unsaturated fatty acid, oleic acid was also present in higher percentage, ranging from 13.3 to $15.9 \%$. Within saturated fatty acids, palmitic acid was present in the highest concentration, ranging from 16.8 to $18.6 \%$ of total identified fatty acids ${ }^{11}$. In addition, $\alpha$ - and $\beta$ - tocopherols were found significant amount in wheat bran oil obtained by $\mathrm{SC}-\mathrm{CO}_{2}$ extraction. The identification of species cultivars with high level of antioxidants, as well as in tracing of biological activities is important for human and other living organisms. Therefore, antioxidants in wheat bran might be quantified by $\mathrm{SC}-\mathrm{CO}_{2}$ extraction for proper using in biological purposes $^{12,11}$.

Nutritionally, bran fractions produced by milling are rich in fiber, minerals, vitamin B6, thiamine, folate and vitamin $\mathrm{E}$ and some phytochemicals; in particular, antioxidants such as phenolic compounds ${ }^{13}$. There are increased interest in the use of plant extracts as natural antimicrobial and antioxidant agents, especially in food, cosmetic, medical and agrochemical areas ${ }^{14-16}$. Phenolic compounds including tannins, terpenoids, alkaloids, and flavonoids in plant extracts have or show good antioxidant and antimicrobial abilities ${ }^{14,17 .}$ 
Collection of Plant Materials

\section{Material and Methods}

Six types of Sudanese wheat bran from Poaceae family collected for this study. The samples Emam, Pohean, Wadielneel, Pladi and Diberawere obtained from Northern state while Argeen sample obtained from Gzeera state.

\section{Preparation of Crude Plant Extracts}

Fifty grams $(50 \mathrm{gm})$ of each of the six types of the wheat bran extracted with $250 \mathrm{ml}$ of different solvents as petroleumether, ethyl acetate, chloroform using a standard soxhlet apparatus for 8 hours at $40^{\circ} \mathrm{C}, 60^{\circ} \mathrm{C}$, and $50^{\circ} \mathrm{C}$ respectively. The residue of petroleum ether was dried and extracted with ethanol using a standard soxhlet apparatus for 8 hours at $60^{\circ} \mathrm{C}$. A water extract was also prepared using cold extraction for 2 hours. All samples kept forfurther analysis. Five (5) $\mu \mathrm{g}$ from each extract sample taken for testing the antioxidant activity using 2.2 Di-(4-tert-octylphenyl)-1-picryl-hydrazyl. For testing the antimicrobial activity, $1 \mathrm{mg}$ from each extract sample taken. The physiochemical propertieswere done for the most two active of the petroleum ether extracts.

\section{Procedure of Biological Activities \\ Antioxidant Activity using Di Phenyl Picrayl Hydrazine Radical Scavenging Assay}

The DPPH radical scavenging was determined according to the method of Shimada ET. al. (1992) ${ }^{18}$. With modification. In 96-wells plate, the test samples were allowed to react with 2.2Di (4- tert-octylphenyl)-1picryl-hydrazyl stable free radical (DPPH) for half an hour at $37 o C$. The concentration of DPPH kept as $(300 \mu \mathrm{m})$. The test samples dissolved in DMSO while DPPH was prepared in ethanol. After incubation, decrease in activity by samples was determined in comparison with a DMSO treated control group. All tests and analysis run in triplicate ${ }^{19}$.

\section{Preparation and Test for Antimicrobial and Antibacterial Activity}

The bacterial suspensions were prepared by aseptically distributing One ml aliquots of a 24 hours broth culture of the test organisms onto nutrient agar slopes and incubated at $37^{\circ} \mathrm{C}$ for 24 hours. The bacterial growth harvested and washed off with $100 \mathrm{ml}$ sterile normal saline, to produce a suspension containing about $10^{8}$ $10^{9}$ C.F.U/ $\mathrm{ml}$. The suspension was stored in the refrigerator at $4^{\circ} \mathrm{C}$ until used. The average number of viable organisms per $\mathrm{ml}$ of the stock suspension was determined by means of the surface viable counting technique (Milesand Misra, 1938). Serial dilutions of the stock suspension made in sterile normal saline solution and $0.02 \mathrm{ml}$ volumes of the appropriate dilution transferred by micropipette onto the surface of dried nutrient agar plates. The plates allowed to stand for two hours at room temperature for the drops to dry and then incubated at $37^{\circ} \mathrm{C}$ for 24 hours. After incubation, the number of developed colonies in each drop counted. The average number of colonies per drop $(0.02 \mathrm{ml})$ multiplied by 50 and by the dilution factor to give the viable count of the stock suspension, expressed as the number of colony forming units per ml suspension. Each time a fresh stock suspension was prepared; all the above experimental conditions were maintained constant so that suspensions with very close viable counts obtained. For testing the antibacterial Activity, the cup-plate agar diffusion method (Kavanagh, 1972) adopted with some minor modifications to assess the antibacterial activity of the prepared extracts. One $\mathrm{ml}$ of the standardized bacterial stock suspension $10^{8}-10^{9} \mathrm{C} . \mathrm{F} . \mathrm{U} / \mathrm{ml}$ were thoroughly mixed with $100 \mathrm{ml}$ of molten sterile nutrient agar which was maintained at $45^{\circ} \mathrm{C}$. Twenty (20) mlaliquots of the inoculated nutrient agar distributed into sterile Petri-dishes. The agar left to set and in each of these plates 4 cups (10 mm in diameter) cut using a sterile corn borer (No. 4) and agar discs removed. Alternate cups filled with 0.1 $\mathrm{ml}$ sample of each extracts using automatic micro liter pipette, and allowed to diffuse at room temperature for two hours. The plates then incubated in the upright position at $37^{\circ} \mathrm{C}$ for 18 hours. Two replicates carried out for each extract against each of the test organisms. After incubation, the diameters of the resultant growth inhibition zones measured. Averaged and the mean values were tabulated. Preparation and Test for Antifungal Activity The fungal suspensions were prepared by aseptically distributing One ml aliquots of a 48 hours broth culture of the test organisms onto sabourd agar slopes and incubated at $25^{\circ} \mathrm{C}$ for 48 hours. The van gall growth was harvested and washed off with $100 \mathrm{ml}$ sterile normal saline, to produce a suspension containing about $10^{8}-10^{9}$ C.F.U/ $\mathrm{ml}$. The suspension was stored in the refrigerator at $4^{\circ} \mathrm{C}$ until used. The average number of viable organisms per $\mathrm{ml}$ of the stock suspension was determined by means of the surface viable counting technique (Miles and Misra, 1938). Serial dilutions of the stock suspension were made in sterile normal saline solution and $0.02 \mathrm{ml}$ volumes of the appropriate dilution were transferred by micropipette onto the surface of dried nutrient agar plates. The plates allowed to stand for two hours at room temperature for the drops to dry and then incubated at $25^{\circ} \mathrm{C}$ for 48 hours. After incubation, the number of developed colonies in each drop counted. The average number of colonies per drop $(0.02 \mathrm{ml})$ multiplied by 50 and by the dilution factor to give the viable count of the stock suspension, expressed as the number of colony forming units per ml suspension. Each time a 
fresh stock suspension was prepared; all the above experimental conditions were maintained constant so that suspensions with very close viable counts obtained. For testing the antifungal Activity, the cup-plate agar diffusion method (Kavanagh, 1972) adopted with some antifungal activity of the prepared extracts. One $\mathrm{ml}$ of the standardized fungal stock suspension $10^{8}-10^{9}$ C.F.U/ml were thoroughly minor modifications to assess the mixed with $100 \mathrm{ml}$ of molten sterile nutrient agar which was maintained at $45 \circ \mathrm{o}$. Twenty (20) mlaliquots of the inoculated nutrient agar distributed into sterile Petri-dishes. The agar left to set and in each of these plates 4 cups (10 mm in diameter) cut using a sterile corn borer (No. 4) and agar discs removed. Alternate cups filled with 0.1 $\mathrm{ml}$ sample of each extracts using automatic micro liter pipette, and allowed to diffuse at room temperature for two hours. The plates then incubated in the upright position at $25^{\circ} \mathrm{C}$ for 18 hours. Two replicates carried out for each extract against each of the test organisms. After incubation, the diameters of the resultant growth inhibition zones measured. Averaged and the mean values were tabulated. Bacterial and Fungal Test microorganisms ${ }^{19}$ :

Bacillus subtilis ..................... NCTC 8236 (Gram + ve bacteria)

Escherichia coli................................ ATCC 25922(Gram -ve bacteria)

Pseudomonas aeruginosa ................ ATCC 27853 (Gram -ve bacteria)

Staphylococcus aureus ................... ATCC 25923(Gram +ve Bacteria)

Candida albicans ............................. ATCC 7596

Aspergillusniger .............................. ATCC 9763

\section{Preparation and Separation Of Ethanolic Extract of the Wheat Bran Using a Laboratory Column}

$250 \mathrm{~g}$ of Pladi type of the wheat bran extracted with ethanol 95 by soxhlet extractor. The ethanolic extract was concentrated for separation with a laboratory column. The eluted solvents were petroleum ether, ethyl acetate, chloroform, acetone and ethanol. The fractions collected into fifteen (15) ones and all of them analyzed by Infrared Spectrophotometer. Three (3) of the fractions were selected after observing the IR charts for GC/MS analysis. The results of separation and the suggested structure of the MS detector recorded in charts.

\section{Biological Activities of Wheat Bran Extracts}

\section{Result and discussion}

\section{Antioxidant Activity of Wheat Bran Extracts}

Tables (3.1-3.5) exhibited the antioxidant activities of different extracts (petroleum ether, ethanol, ethyl acetate, chloroform, and water) of six types of the wheat bran.

Table 3.1: Antioxidant activity of Petroleum ether

\begin{tabular}{||c||c||}
\hline \hline Sample Cod & \%RSA \pm SD (DPPH) \\
\hline \hline Emam & $54 \pm 0.1$ \\
\hline \hline Pohean & D.N \\
\hline \hline Wadielneel & $66.4 \pm 0.01$ \\
\hline \hline Argean & Inactive \\
\hline \hline Pladi & $9.3 \pm 0.03$ \\
\hline \hline Dibera & $6.3 \pm 0.05$ \\
\hline \hline \hline
\end{tabular}

The highest antioxidant activity of the Petroleum ether extract was in Wadielneel followed by Emam and Pladi.

Table3.2: Antioxidant activity of Ethanol extract

\begin{tabular}{||c||c||}
\hline \hline Sample Cod & \%RSA \pm SD (DPPH) \\
\hline \hline Emam & $17.7 \pm 0.01$ \\
\hline \hline Pohean & $21.6 \pm 0.01$ \\
\hline \hline Wadielneel & $35.4 \pm 0.01$ \\
\hline \hline Argean & $34.6 \pm 0.02$ \\
\hline \hline Pladi & $50.7 \pm 0.02$ \\
\hline \hline Dibera & $10.4 \pm 0.01$ \\
\hline \hline
\end{tabular}

In ethanolic extract, Pladi is the highet in antioxidant activity followed by Wadielneel and then Argeen. It has well established that free radical scavenging activity of wheat extracts is mainly due to phenolic compounds.

Table 3.3: Antioxidant activity of Ethyl acetate extract

\begin{tabular}{||c||c||}
\hline \hline Sample Cod & \%RSA \pm SD (DPPH) \\
\hline \hline Emam & $26.9 \pm 0.07$ \\
\hline \hline Pohean & $18.5 \pm 0.004$ \\
\hline \hline Wadielneel & $21.3 \pm 0.03$ \\
\hline
\end{tabular}




\begin{tabular}{||c||c||}
\hline \hline Argean & $13.2 \pm 0.07$ \\
\hline \hline Pladi & $14.1 \pm 0.2$ \\
\hline \hline Dibera & $42.8 \pm 0.03$ \\
\hline \hline
\end{tabular}

Dibeira showed the highest antioxidant activity in ethyl acetate extract.

Table3.4: Antioxidant activity of Chloroform

\begin{tabular}{||c||c||}
\hline \hline Sample Cod & \%RSA \pm SD (DPPH) \\
\hline \hline Emam & Inactive \\
\hline \hline Pohean & 14 \\
\hline \hline Wadielneel & Inactive \\
\hline \hline Argean & $61.2 \pm 0.02$ \\
\hline \hline Pladi & Inactive \\
\hline \hline Dibera & $8.6 \pm 0.01$ \\
\hline \hline
\end{tabular}

The most antioxidant active in chloroform extract is Argeen extract.

Table 3.5: Antioxidant activity of Water extract

\begin{tabular}{||c||c||}
\hline \hline Sample Cod & \%RSA \pm SD (DPPH) \\
\hline \hline Emam & $17.7 \pm 0.06$ \\
\hline \hline Pohean & Inactive \\
\hline \hline Wadielneel & $6.6 \pm 0.03$ \\
\hline \hline Argean & $5.7 \pm 0.01$ \\
\hline \hline Pladi & $12.7 \pm 0.01$ \\
\hline \hline Emam & $17.7 \pm 0.06$ \\
\hline \hline
\end{tabular}

The Water extract showed negligible value for the antioxidant activity.

\section{Antimicrobial Activity of the Wheat Bran Extracts}

\section{Antimicrobial Activity of Wheat Bran Petroleum ether Extract}

As Shown in table 3.6. Pladi and Dibera petroleum ether extracts showed various antibacterial and antifungal activities (sensitive and intermediate) towards the selected bacteria and fungi in the study, these activities were the most active ones of the wheat bran extracts. While Argeen showed intermediate antibacterial activity towards Pseudomonas aeruginosa. All of the petroleum ether extracts of the other types of the wheat bran were inactive towards the selected bacteria and fungi in the study.

Table 3.6: Microbial Activity of the Petroleum ether Extract.

\begin{tabular}{|c|c|c|c|c|c|c|}
\hline \multirow{3}{*}{$\begin{array}{l}\text { Plants name } \\
\text { Extract of }\end{array}$} & \multicolumn{6}{|c|}{ Antimicrobial activities } \\
\hline & \multicolumn{4}{|c|}{ Antibacterial activity } & \multicolumn{2}{|c|}{ 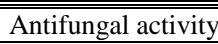 } \\
\hline & 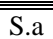 & B.s & P.s & E.c & A.s & 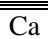 \\
\hline Emam & - & - & - & - & - & - \\
\hline Pohean & 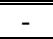 & 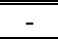 & 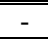 & 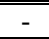 & 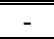 & 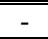 \\
\hline "Wadielneel & - & - & - & - & - & - \\
\hline Argean & - & $\begin{array}{l}- \\
\end{array}$ & 17 & - & - & - \\
\hline Pladi & 15 & 20 & 18 & 23 & 21 & 34 \\
\hline Dibera & 17 & 18 & 16 & 24 & 22 & 30 \\
\hline
\end{tabular}

E.C: Escherichia coli, P.S: Pseudomonas aeruginosa, B.S: Bacillus subtilis, S.a: Staphylococcus aureus;

Ca:Candida albicans, A.S: Aspergillus niger.

\section{Scale of interpretation:}

$>18 \mathrm{~mm}(\mathrm{MIZD})=$ sensitive

$14-18 \mathrm{~mm}(\mathrm{MIZD})=$ intermediate

$<14 \mathrm{~mm}(\mathrm{MIZD})=$ resistant 


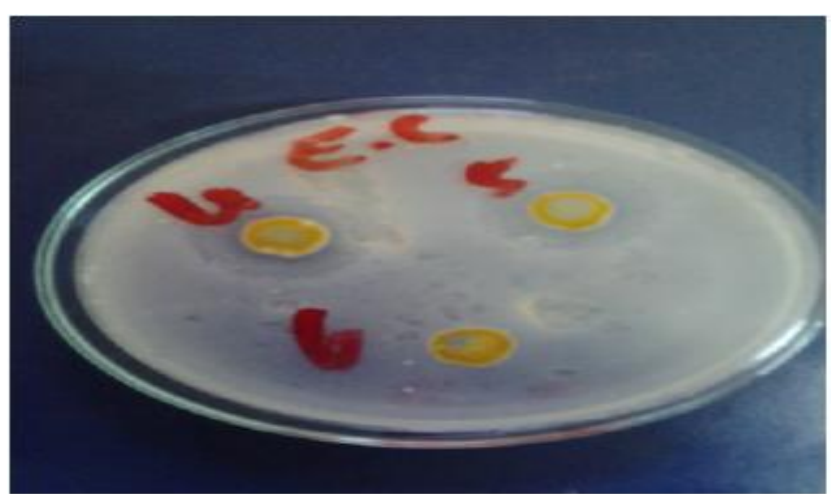

Petroleum ether (Debera (4))

Petroleum ether (Pladi (5))

Petroleum ether (Argeen (6))

Escherichia coli

ATCC 25922(Gram -ve bacteria)

Petroleum ether (Debera (4))

Petroleum ether (Pladi (5))

Petroleum ether (Argeen (6))

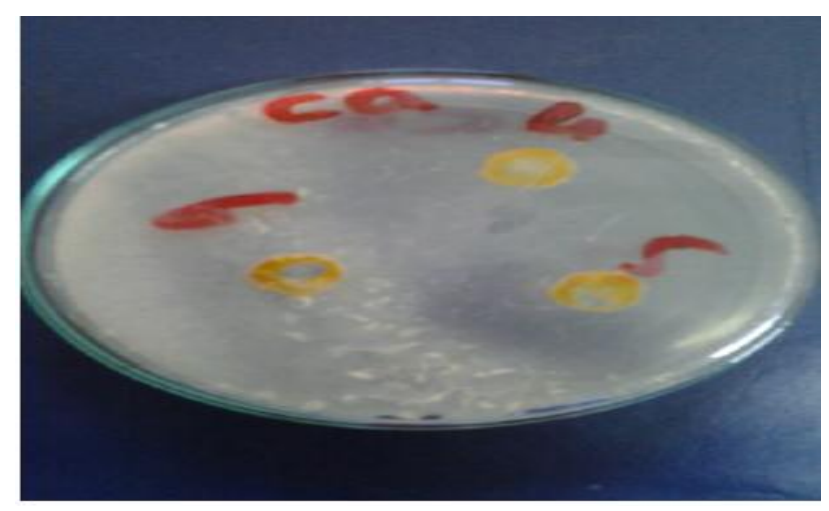

Petroleun ether (Argeen (6))

Candida albicans

(ATCC 7596)

\section{Microbial Activity of Wheat Bran Ethanolic Extract}

In table 3.7 Dibera ethanolic extract showed intermediate antibacterial activity towards Escherichia coli and Staphylococcus aureus. Whereas the other types were found to be resistant to the other selected bacteria. Emam, Argeen and Wadielneel showed intermediate antifungal activity towards Candida albicans. While the extract of the other types were found to be resistant to the fungus. Wadielneel, Argeen, Emam and Dibera ethanolic extracts showed intermediate antifungal activity to Aspergillus niger while Pohean and Pladi were found to be resistant to the fungus.

Table 3.7: Microbial Activity of Ethanolic Extract

\begin{tabular}{|c|c|c|c|c|c|c|}
\hline \multirow{3}{*}{$\begin{array}{l}\text { Plants name } \\
\text { Extract of }\end{array}$} & \multicolumn{6}{|c|}{ " Antimicrobial activities } \\
\hline & \multicolumn{4}{|c|}{ Antibacterial activity } & \multicolumn{2}{|c|}{ Antifungal activity } \\
\hline & S.a & B.s & P.s & E.c & A.s & $\overline{\mathrm{Ca}}$ \\
\hline Emam & 12 & 13 & 12 & 13 & 17 & 16 \\
\hline Pohean & 13 & 13 & 12 & 13 & 13 & 13 \\
\hline "Wadielneel & 12 & 12 & 13 & 13 & 18 & 15 \\
\hline A Argean & 12 & 12 & 12 & 12 & 18 & 16 \\
\hline Pladi & 12 & 15 & 12 & 13 & 12 & 13 \\
\hline Dibera & 14 & 12 & 12 & 14 & 14 & 111 \\
\hline
\end{tabular}

E.C: Escherichia coli, P.S: Pseudomonas aeruginosa, B.S: Bacillus subtilis, S.a: Staphylococcus aureus; Ca:Candida albicans, A.S: Aspergillus niger

\section{Scale of interpretation:}

$>18 \mathrm{~mm}(\mathrm{MIZD})=$ sensitive

$14-18 \mathrm{~mm}(\mathrm{MIZD})=$ intermediate

$<14 \mathrm{~mm}(\mathrm{MIZD})=$ resistant 


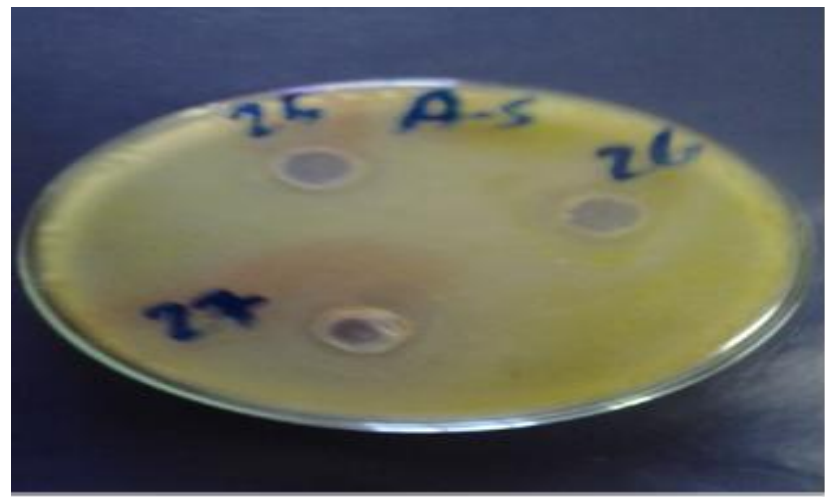

Extract of Ethanol (Pohean (1))

Extract of Ethanol (Debera (2)

Extract of Ethanol (Pladi (3))

Aspergillus niger

ATCC 9763

Microbial Activity of Wheat Bran Ethyl acetate Extract

In Table 3.8. The types Pladi, Dibera, and Argeen found to be sensitive antifungal activity to Aspergillusniger. While Pladi was found to be sensitive antibacterial to Pseudomonasae ruginosa and Dibera was found to be sensitive as antibacterial to Staphylococcus aureus.Emam showed

Sensitive antibacterial activity to seudomonas aeruginosa. The extracts of the other types showed intermediate and resistant as antifungal and antibacterial.

Table 3.8: Microbial Activity of Ethyl acetate Extract

\begin{tabular}{|c|c|c|c|c|c|c|}
\hline Plants name & \multicolumn{6}{|c|}{ Antimicrobial activities } \\
\hline & \multicolumn{4}{|c|}{ Antibacterial activity } & \multicolumn{2}{|c|}{ Antifungal activity } \\
\hline Extract of & S.a & B.s & P.s & E.c & A.s & $\mathrm{Ca}$ \\
\hline Emam & 15 & 18 & 21 & - & 18 & 14 \\
\hline Pohean &  & - & 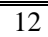 & 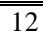 & "18 & - \\
\hline W Wadielneel & 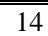 & 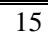 & 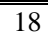 & ב- & 1717 & 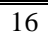 \\
\hline Argean & $\overline{176}$ & 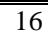 & 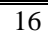 & 15 & 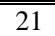 & 15 \\
\hline Pladi & 17 & 17 & 19 & 14 & 222 & 16 \\
\hline $\begin{array}{l}\text { Dibera } \\
\end{array}$ & 20 & 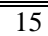 & 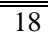 & 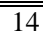 & 24 & 18 \\
\hline
\end{tabular}

E.C: Escherichia coli, P.S: Pseudomonas aeruginosa, B.S: Bacillus subtilis, S.a: Staphylococcus aureus; Ca:Candida albicans, A.S: Aspergillus niger .

\section{Scale of interpretation:}

$>18 \mathrm{~mm}(\mathrm{MIZD})=$ sensitive

14-18mm $($ MIZD $)=$ intermediate

$<14 \mathrm{~mm}(\mathrm{MIZD})=$ resistant



Extracts of ethyl acetate (Argeen (25))

Extracts of ethyl acetate (Pladi (26))

Extracts of ethyl acetate (Debera (27))

Figure 45: Aspergillusniger (ATCC 9763)

Microbial Activity of Wheat Bran Chloroform Extract

In table 3.9. Pladi showed antibacterial activity (sensitive) to Pseudomonas aeruginosa and antifungal activity (sensitive) to Aspergillusniger. The other types of wheat bran chloroform extract showed antibacterial and antifungal activities ranging from intermediate to resistant for the selected bacteria and fungi. 
Table 3.9: Microbial Activity of Chloroform Extract

\begin{tabular}{|c|c|c|c|c|c|c|}
\hline \multirow{3}{*}{$\begin{array}{l}\text { Plants name } \\
\text { Extract of } \\
\end{array}$} & \multicolumn{6}{|c|}{ Antimicrobial activities } \\
\hline & \multicolumn{4}{|c|}{ Antibacterial activity } & \multicolumn{2}{|c|}{ Antifungal activity } \\
\hline & S.a & B.s & P.s & E.c & A.s & $\mathrm{Ca}$ \\
\hline Emam & 15 & 13 & 14 & 12 & 17 & 15 \\
\hline Pohean & 13 & - & - & - & - & - \\
\hline Wadielneel & 15 & 13 & 15 & 13 & 16 & 16 \\
\hline Argean & 14 & 14 & 14 & 12 & 15 & 17 \\
\hline Pladi & 15 & 16 & 19 & - & 19 & 12 \\
\hline Dibera & 14 & - & - & - & - & - \\
\hline
\end{tabular}

E.C: Escherichia coli, P.S: Pseudomonas aeruginosa, B.S: Bacillus subtilis, S.a: Staphylococcus aureus;

Ca:Candida albicans, A.S: Aspergillus niger .

\section{Scale of interpretation:}

$>18 \mathrm{~mm}($ MIZD $)=$ sensitive

14-18mm $($ MIZD) $=$ intermediate

$<14 \mathrm{~mm}(\mathrm{MIZD})=$ resistant

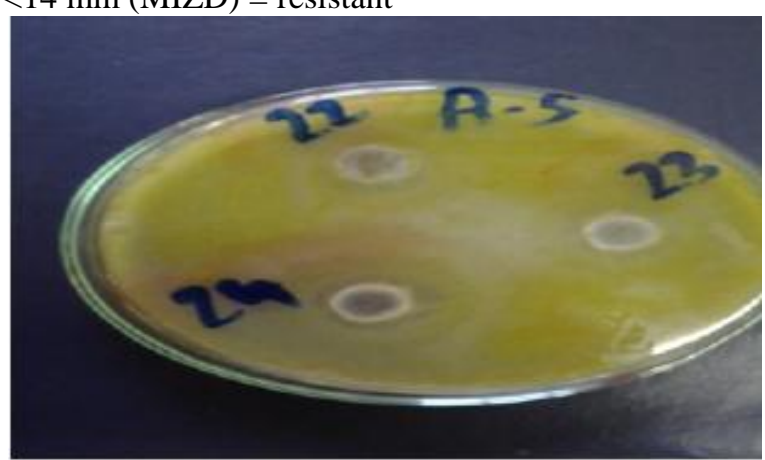

Extracts of chloroform (Pladi (22))

Extracts of ethyl acetate (Emam (23))

Extracts of ethyl acetate (Wadielneel (24))

Aspergillus niger

ATCC 9763

\section{Microbial Activity of Wheat Bran Water Extract}

Table 3.10. Showed that Dibera water extract was the most active as antifungal and as antibacterial to the all selected bacteria and fungi. Pladi showed antibacterial activity (sensitive) to Escherichia coli and to Bacillus subtilis. In addition, it showed antifungal activity (sensitive) to the two fungi Candida albicans and Aspergillusniger. Emam extract showed antibacterial activity (sensitive) to Escherichia c oli,B acillus subtilis, and Staphylococcus aureus, and antifungal activity (sensitive) to Aspergillusniger. The water extract for the remaining types showed intermediate activities to the selected bacteria and fungi.

Table 3.10: Microbial Activity of Water Extract

\begin{tabular}{|c|c|c|c|c|c|c|}
\hline \multirow{3}{*}{$\begin{array}{l}\text { Plants name } \\
\text { Extract of } \\
\end{array}$} & \multicolumn{6}{|c|}{ Antimicrobial activities } \\
\hline & \multicolumn{4}{|c|}{ Antibacterial activity } & \multicolumn{2}{|c|}{ Antifungal activity } \\
\hline & S.a & B.s & P.s & E.c & A.s & $\mathrm{Ca}$ \\
\hline Emam & 22 & 23 & 17 & 19 & 30 & - \\
\hline Pohean & 17 & 15 & 13 & 15 & 21 & - \\
\hline Wadielneel & - & - & - & - & 20 & - \\
\hline Argean & 16 & 15 & 15 & 17 & 20 & 18 \\
\hline Pladi & 17 & 19 & 16 & 23 & 24 & 19 \\
\hline Dibera & 22 & 20 & 20 & 20 & 30 & 19 \\
\hline
\end{tabular}

E.C: Escherichia coli, P.S: Pseudomonas aeruginosa, B.S: Bacillus subtilis, S.a: Staphylococcus aureus; Ca:Candida ,albicans, A.S: Aspergillus niger

Scale of interpretation:

$>18 \mathrm{~mm}(\mathrm{MIZD})=$ sensitive

14-18 $\mathrm{mm}(\mathrm{MIZD})=$ intermediate

$<14 \mathrm{~mm}(\mathrm{MIZD})=$ resistant 


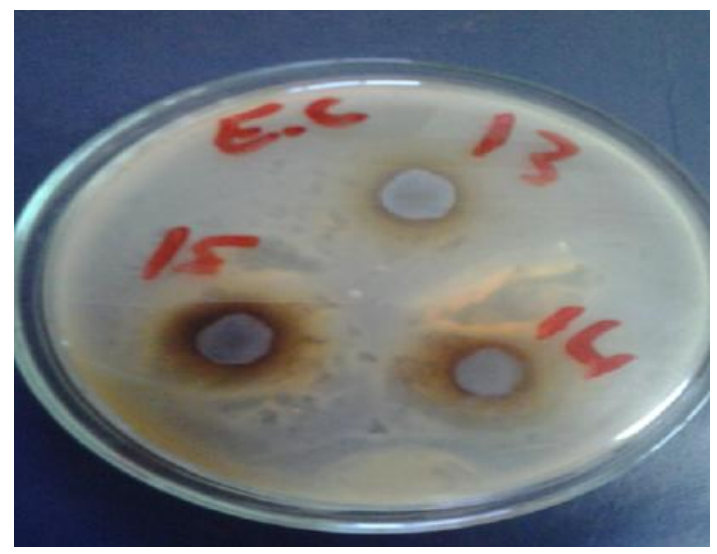

Extracts of Water (Argeen (13))

Extracts of Water (Pladi (14))

Extracts of Water (Debera (15))

Figure 47 Escherichia coli ATCC 25922(Gram -ve bacteria)

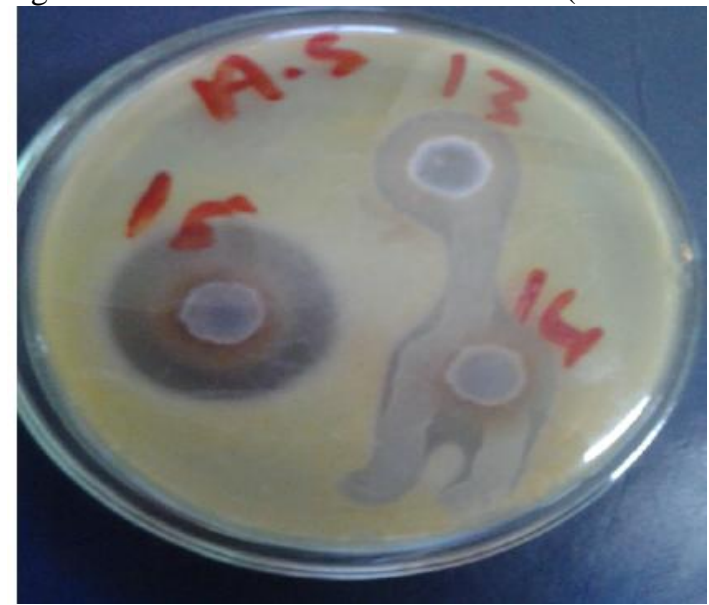

Extracts of Water (Argeen (13))

Extracts of Water (Pladi (14))

Extracts of Water (Debera (15))

Aspergillus niger

ATCC 9763)



Chart 3:1 G.C of Petroleum ether Fraction 1

Chart 3:2 G.C of Petroleum ether Fraction 2

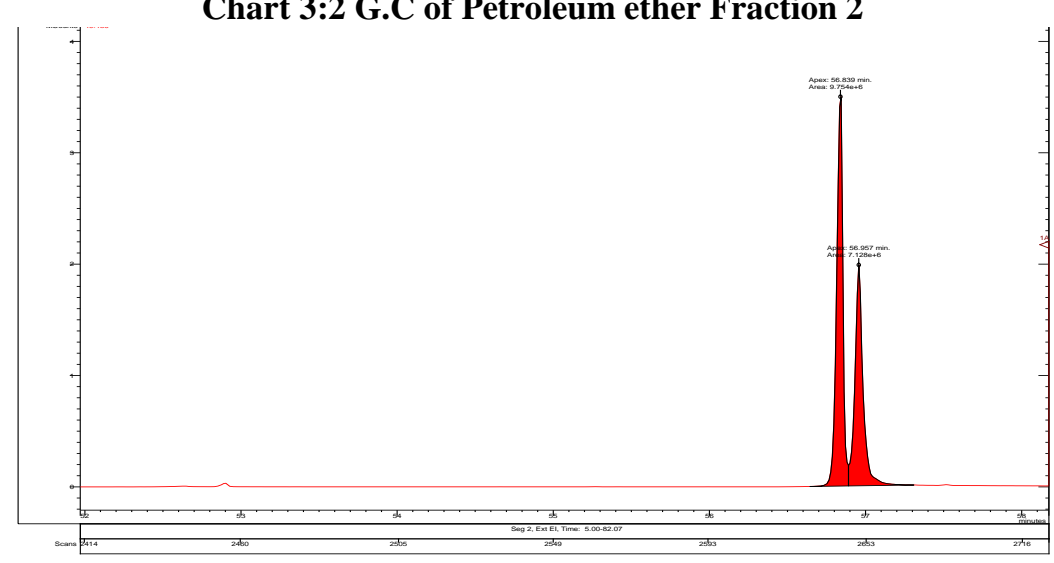




\section{Chart 3:3 G.C of Acetone Fraction 2}

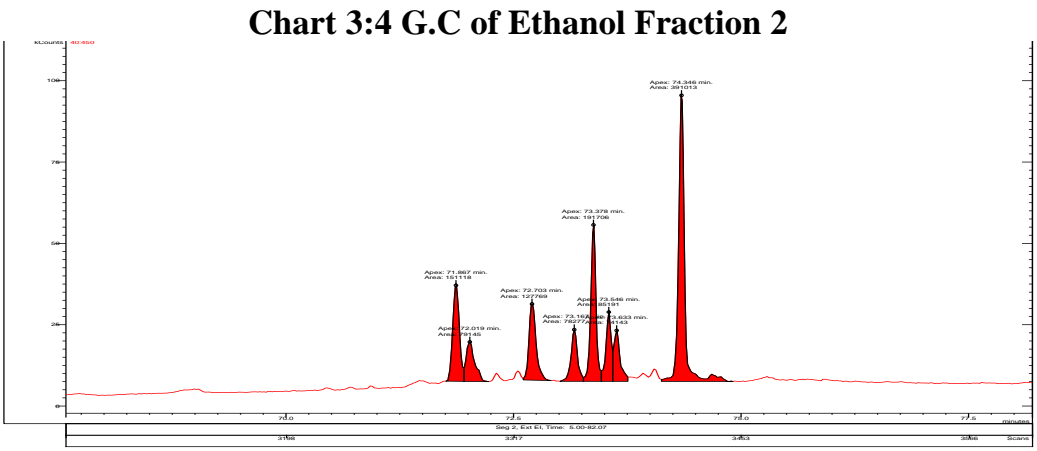

\section{Conclusion}

The results conclude that the Wheat bran contains Antioxidant Activity. Using DiPhenyl Picrayl Hydrazine Radical Scavenging Assay, the highest antioxidant activity of the Petroleum ether extract found to be in Wadielneel. In ethanolic extract, Pladi is the highest in antioxidant activity followed by Wadielneel and then Argeen. The free radical scavenging activity of wheat extracts is mainly due to phenolic compounds. It is also notable that this product is a potential source of antimicrobial activity that act mainly on Gram-positive and Gram-negative bacteria and fungous. Thus, it can be an efficient protective agent as antioxidant and antibacterial additives in food systems. The overall results shows that, these by-products are very good source of bioactive compounds of beneficial effects on health.

\section{Acknowledgement}

The authors would like to thank everyone who contributed to complete this work.

\section{References}

[1]. Surget, A.; Barron, C. histology du grain du ble. Industrie des cereals. 145: 3-7, (2005)

[2]. Alabaster, Z. Tang, and N. Shivapurkar. "Inhibition by wheat bran cereals of the development of aberrant crypt foci and colon tumors". Food and Chemical Toxicology, 35, pp. 517-522, (1997).

[3]. Moller, M.E. R. Dahl, and O. C. Bockman. "A possible role of the dietary fibre product, wheat bran, as a nitrite scavenger", Food Chemistry and Toxicology, 26, pp. 841-845, (1988).

[4]. Halliwell. B, "Antioxidants in human health and diseases," Annu. Rev. Nutr., 16, pp. 33-50, (1992).

[5]. Truswell. A. S. "Cereal grains and coronary heart disease,” Eur. J. Clin. Nutr, 56, pp. 1-14, (2003).

[6]. Haley. L. Yu, Perret S., J.; Harris M. 'Antioxidant properties of hard winter wheat extracts,' Food Chem, 78, pp. 457-461, (2002).

[7]. Andreasen. M. F, Kroon, P. A., Williamson. G. and M. T. Garcia-Conesa. "Intestinal release and uptake of phenolic antioxidant diferulic acids , Free Radical Biol. Med., 31, pp. 304-314, (2001).

[8]. Haley. L. Yu. Perret S., J, Harris M., Wilson J.; M. Qian. -Free radical scavenging properties of wheat extracts, 'J. Agric. Food Chem., 50, pp. 1619-1624, (2002)

[9]. Yu, L.; Haley, S.; Perret, J.; Harris, M.; Wilson, J.; Qian, M.; 'Free radical scavenging properties of wheat extracts' , J. Agric. Food Chem., 50, pp. 1619-1624, (2002).

[10]. Adom, K. K.; R. H. Liu. 'Rapid peroxyl radical scavenging capacity(PSC) assay for assessing both hydrophilic and lipophilic antioxidants', J. Agric. Food Chem., 53, pp. 6572-6580,(2005).

[11]. Kwon, K-T; Uddin, M- S; Jung, G-W; Sim, J-E; Chun. B-S; 'Supercritical Carbon Dioxide Extraction of Phenolics and Tocopherols Enriched Oil from Wheat Bran' World Academy of Science, Engineering and Technology, 4: 04-27, (2010).

[12]. Gelmez, N. S. Kincal, ; M. E. Yener, Optimization of supercritical carbon dioxide extraction of antioxidants from roasted wheat germ based on yield, total phenolic and tocopherol contents, and antioxidant activities of the extracts, J. Supercrit. Fluids, 48, pp. 217-2240, (2009)

[13]. shewry P. The Healthgrainprogramme opens new opportunities for improving wheat for nutrition and health. Nutr Bull. 2009;34:225-231

[14]. Gurjar M S, Ali S, Akhtar M, et al., Efficacy of plant extracts in plant disease management. Agricultural Sciences, 2012; 3: 425433.

[15]. Merkl R, HrádkoVá I, Filip V, et al., Antimicrobial and antioxidant properties of phenolic acids alkyl esters. Czech J Food Science, 2010; 28: 275-279.

[16]. Roby M H H, Sarhan M A, Selim K A H, et al., Evaluation of antioxidant activity, total phenols and phenolic compounds in thyme (Thymus vulgaris L.), sage (Salvia officinalis L.), and marjoram (Origanummajorana L.) extracts. Industrial Crops and Products, 2013; 43: 827-831

[17]. Gutiérrez-Larraínzar M, Rúa J, Caro I, et al., Evaluation of antimicrobial and antioxidant activities of natural phenolic compounds against foodborne pathogens and spoilage bacteria. Food Control, 2012; 26: 555-563.

[18]. Shimada, K.; Fujikawa, K.; Yahara, K.; Nakamura, T. Antioxidative properties of xanthan on the antioxidation of soybean oil in cyclodextrin emulsion. J Agric Food Chem; 40:945-8. (1992).

[19]. Kavanagh, F. Analytical Microbiology. Academic Press, York, London, 11:11, (1972). 